\title{
BETTERMENT OF DICLOFENAC-INDUCED NEPHROTOXICITY BY PENTOXIFYLLINE THROUGH MODULATION OF INFLAMMATORY BIOMARKERS
}

\author{
HAYDER M. AL-KURAISHY ${ }^{*}$, ALI I. AL-GAREEB ${ }^{2}$, NAWAR RAAD HUSSIEN ${ }^{2}$
}

${ }^{1}$ Department of Clinical Pharmacology, Medicine and Therapeutics, College of Medicine, Al-Mustansiriya University, Baghdad, Iraq ${ }^{2}$ Department of Clinical Pharmacology, College of Medicine, Al-Mustansiriya University, Baghdad, Iraq. Email: hayderm36@yahoo.com

Received: 19 November 2018, Revised and Accepted: 28 December 2018

\section{ABSTRACT}

Objectives: Diclofenac-induced nephrotoxicity is caused by oxidative stress which leads to lipid peroxidation and formation of free radicals. Pentoxifylline can ameliorates renal tissue injury by its anti-inflammatory, antifibrotic, and antioxidant effects, so it mitigates the progression of renal diseases. Therefore, the aim of this study was to evaluate the nephroprotective effects of pentoxifylline on diclofenac-induced nephrotoxicity in rats.

Methods: A total of 30 male Sprague-Dawley rats were allocated into three groups, Group 1 (n=10): Rats treated with distilled water 5 ml/kg plus normal saline $5 \mathrm{ml} / \mathrm{kg}$ for 12 days, Group 2 (n=10): Rats treated with distilled water $5 \mathrm{ml} / \mathrm{kg}$ plus diclofenac $15 \mathrm{mg} / \mathrm{kg}$ for 12 days, and Group 3 ( $\mathrm{n}=10)$ : Rats treated with pentoxifylline $100 \mathrm{mg} / \mathrm{kg}$ plus diclofenac $15 \mathrm{mg} / \mathrm{kg}$ for 12 days. Blood urea, creatinine, malondialdehyde (MDA), superoxide dismutase (SOD-1), glutathione reductase (GSH), neutrophil gelatinase associated lipocalin (NGAL), kidney injury molecules (KIM-1) vitronectin (VTN), integrin (ITG) , interleukin-18 (IL-18) and cystatin-C were used to measure the severity of nephrotoxicity.

Results: Diclofenac-induced nephrotoxicity led to significant elevation in blood urea, serum creatinine, MDA, IL-18, KIM-1, NGAL, serum ITG, and VTN with decrease of SOD-1 and GSH sera levels $\mathrm{p}<0.05$. Treatment with pentoxifylline showed no significant effect on all biomarker levels compared to diclofenac group except on serum level KIM-1 and serum VTN, $\mathrm{p}<0.05$.

Conclusion: Pentoxifylline produced significant nephroprotective effect on diclofenac-induced nephrotoxicity through modulation of inflammatory biomarkers.

Keywords: Nephrotoxicity, Diclofenac, Pentoxifylline.

(C) 2019 The Authors. Published by Innovare Academic Sciences Pvt Ltd. This is an open access article under the CC BY license (http://creativecommons. org/licenses/by/4. 0/) DOI: http://dx.doi.org/10.22159/ajpcr.2019.v12i3.30829

\section{INTRODUCTION}

Nephrotoxicity is a renal-specific situation in which the toxic metabolites do not excrete normally due to toxic agents and drugs [1]. Nephrotoxic agents lead to interstitial nephritis and glomerulonephritis. Acute interstitial nephritis is caused by nonsteroidal anti-inflammatory drug (NSAIDs) and rifampicin, while chronic interstitial nephritis is caused by lithium and calcineurin inhibitors [2].

Proximal renal tubular cells are susceptible to the toxic effect of different drugs and agents due to extended exposure and reabsorbing process. Nephrotoxic drugs lead to damage of the proximal renal tubules through stimulation of oxidative stress, impairments of mitochondrial functions, and interfering with reabsorbing tubular transport process [3].

Diclofenac is a NSAID belongs to the structural family of acetic acid derivatives. Diclofenac is used as analgesic, anti-inflammatory, and antipyretic agent [4].

The foremost mechanism of diclofenac is through the inhibition of prostaglandin-endoperoxide synthase which also called cyclooxygenase-2 (COX-2). Diclofenac inhibits COX-1 about 10-fold than COX-2. It also inhibits lipoxygenase pathway that reduces the production of leukotrienes and other pro-inflammatory autacoids as well diclofenac sodium blocks phospholipase A2 lead to broad and potent anti-inflammatory effect [5].

Long-term treatment with diclofenac causes dose-dependent reduction in the glomerular function. In addition, diclofenac induces autolysis that increases renal intracellular osmolality which is responsible for dilatations of proximal renal tubules [6].
Toxic dose of diclofenac provokes renal mitochondrial dysfunction through the inhibition of mitochondrial complex causes a reduction in adenosine triphosphate (ATP) generation and apoptosis. Thus, antioxidants may play a potential role in prevention of diclofenacinduced nephrotoxicity through attenuation of free radical and oxidative stress effects [7].

Pentoxifylline is a xanthine derivative drug used in the treatment of peripheral vascular diseases [8]. Pentoxifylline has a beneficial effect in nephropathy through reduction of tumor necrosis factor (TNF)- $\alpha$, proteinuria, and microalbuminuria in diabetic patients. Pentoxifylline inhibits leukotriene and TNF synthesis, increases intracellular cAMP, and decreases innate immunity and inflammation. Pentoxifylline also prevents the expression of mRNA levels of TNF- $\alpha$ and antagonize adenosine receptors [9].

Pentoxifylline impedes the reduction of estimated glomerular filtration rate (eGFR) by a mechanism independent of its effects. Pentoxifylline protects the kidney by inhibition of arachidonic acid metabolism. Pentoxifylline ameliorates renal injury through anti-inflammatory, antifibrotic, and antioxidant effects, so it mitigates the progression of renal diseases [10].

There is a positive significant relationship between pentoxifylline therapy and reduction in TNF- $\alpha$ level and albuminuria. Since TNF- $\alpha$ production occurs within the kidneys, So administration of pentoxifylline leads to modulation of its synthesis [11]. Pentoxifylline decreases proteinuria in patients with diabetic neuropathy. As well, pentoxifylline has the ability to reduce proteinuria by two main mechanisms. First, it has the ability to increase the deformability of red blood cells result in lowering of blood viscosity that decreases glomerular pressure and 
proteinuria. The second mechanism is thought to be due to the ability of pentoxifylline to block adenosine receptors since hyperfiltration is associated with high production of renal adenosine [12].

In addition, pentoxifylline ameliorates nephrotic syndrome and membranous glomerulonephritis. Moreover, pentoxifylline reduces proteinuria in patients with advanced and early-onset diabetic nephropathy [13]

Therefore, the aim of this study was to evaluate the nephroprotective effects of pentoxifylline on diclofenac-induced nephrotoxicity in rats

\section{METHODS}

\section{Study design}

A total of 30 male Sprague-Dawley rats were used, which were gained from the National Center for Drug Control and Research. Rats age ranged from 3 to 4 months and their body weight ranged from 200 to $400 \mathrm{~g}$. The animals were isolated as three rats in each sterilized cage and placed with suitable temperature of $22-25^{\circ} \mathrm{C}$ and artificial $12 / 12$ light-dark cycle. They left for 1 week for adaptation without any intervention with free access to normal chow pellets and water. This study was permitted by specific Scientific Adjudicators and Ethical Committee in the Medical Board College of Medicine, Al-Mustansiriya, Baghdad, Iraq. Humane care for animals was according to the guide to the care and the use of laboratory animal. All drugs were purchased from private pharmacy, diclofenac sodium ampule $75 \mathrm{mg} / 3 \mathrm{ml}$ (Almiral ${ }^{\circledR}$, Czech Republic), and pentoxifylline $400 \mathrm{mg}$ tablet (Trental ${ }^{\circledR}$, Canada). The study protocol and method for induction of nephrotoxicity were according to Singh et al. method [14].

Group 1 ( $n=10$ ): Rats treated with distilled water $5 \mathrm{ml} / \mathrm{kg}$ plus normal saline $5 \mathrm{ml} / \mathrm{kg}$ for 12 days. Group $2(n=10)$ : Rats treated with distilled water $5 \mathrm{ml} / \mathrm{kg}$ plus diclofenac $15 \mathrm{mg} / \mathrm{kg}$ for 12 days. Group 3 ( $n=10)$ : Rats treated with pentoxifylline $100 \mathrm{mg} / \mathrm{kg}$ plus diclofenac $15 \mathrm{mg} / \mathrm{kg}$ for 12 days.

At the $13^{\text {th }}$ day of the study, animals were sacrificed and blood samples were centrifugated at $3500 \mathrm{rpm} / 15 \mathrm{~min}$ for biochemical analysis.

\section{Assessment of renal injury biomarkers}

Renal injury was evaluated by measuring specific biomarkers including blood urea, serum creatinine and biomarkers of nephrotoxicity including malondialdehyde (MDA), superoxide dismutase (SOD), glutathione reductase (GSH), Neutrophil Gelatinase Associated Lipocalin (NGAL), kidney injury molecules (KIM-1), interleukin-18 (IL-18), vitronectin (VTN), integrin (ITG) and cystatin-C were measured by enzyme-linked immunosorbent assay kit methods according to the instruction of the manufacture.

\section{Assessment of anthropometric variables}

Length was measured by graduated tape measure from nose to the anus (naso-anal length in $\mathrm{cm}$ ). Rat body weight was measured by specific digital balance in gram. Body mass index was measured by specific equation, body mass index $(\mathrm{BMI})=\mathrm{BW}(\mathrm{grams}) /$ length $(\mathrm{cm})^{2}[15]$.

Estimated eGFR was measured according to Schwartz formula, eGFR $=\mathrm{k} \times$ height $(\mathrm{cm}) /$ serum creatinine $(\mathrm{mg} / \mathrm{dl}), \mathrm{K}=0.55$ [16].

\section{Statistics}

Data of the present study were presented as mean \pm SD. Unpaired Student's $t$-test was used to detect the level of significance between control and treated groups. P value was regarded as statistically significant when it $<0.05$.

\section{RESULTS}

During diclofenac-induced nephrotoxicity, rat body weight was increased to $286.87 \pm 27.24 \mathrm{~g}$ compared to the control group $268.00 \pm 25.01 \mathrm{~g}$ but not significant, $p=0.20$. Rat BMI was increased significantly in diclofenac group compared to the control, $\mathrm{p}=0.0003$. Blood urea was raised significantly in diclofenac group $(70.5 \pm 12.53 \mathrm{mg} / \mathrm{dl})$ compared to the control group $(41.83 \pm 7.46 \mathrm{mg} / \mathrm{dl}), \mathrm{p}=0.0003$, also serum creatinine increased significantly $(1.52 \pm 0.49 \mathrm{mg} / \mathrm{dl})$ compared to control group $(0.7 \pm 0.14 \mathrm{mg} / \mathrm{dl}), p=0.0019$. The estimated $\mathrm{GFR}$ was reduced significantly in diclofenac group $(7.59 \pm 1.7 \mathrm{ml} / \mathrm{min} / 1.73)$ compared to the control $(16.89 \pm 4.21 \mathrm{ml} / \mathrm{min} / 1.37), \mathrm{p}=0.0001$.

Regarding the oxidative stress and endogenous antioxidant capacity, there was insignificant increase in the MDA serum levels in diclofenac group $(427.65 \pm 210.39 \mathrm{ng} / \mathrm{ml})$ compared to the control group $(289.85 \pm 44.18 \mathrm{ng} / \mathrm{ml}), \mathrm{p}=0.14$; also, both SOD-1 and GSH serum level were reduced in diclofenac group compared to control group $\mathrm{p}=0.20$ and $\mathrm{p}=0.49$, respectively.

Concerning the inflammatory and pro-inflammatory biomarkers in diclofenac-induced nephrotoxicity, IL-18 serum level was increased but not significant in diclofenac group from $29.79 \pm 3.27$ to $14.88 \pm 3.02 \mathrm{pg} / \mathrm{ml}$ compared to control group, $\mathrm{p}=0.36$. Moreover, KIM- 1 was significantly raised in diclofenac group $(269.03 \pm 29.61 \mathrm{pg} / \mathrm{ml})$ compared to the control group (73.78 \pm 16.29$), p=0.0001$. However, serum levels of NGAL, ITG, and VTN were insignificantly increased $(p>0.05)$ compared to the control group as shown in Table 1.

Indeed, cystatin-C serum level was insignificantly increased during induction of nephrotoxicity by diclofenac from $0.024 \pm 0.0005 \mathrm{ng} / \mathrm{ml}$ in the control group to $0.0277 \pm 0.009 \mathrm{ng} / \mathrm{ml}$ in the experimental group, $\mathrm{p}=0.33$ (Fig. 1).

The potential effect of pentoxifylline during diclofenac-induced nephrotoxicity showed a significant reduction in BMI $(0.55 \pm 0.01 \mathrm{~g} /$ $\left.\mathrm{cm}^{2}\right)$ compared to diclofenac group $\left(0.64 \pm 0.03 \mathrm{~g} / \mathrm{cm}^{2}\right), \mathrm{p}=0.0001$. Pentoxifylline significantly improves estimated GFR from $7.59 \pm 1.7 \mathrm{ml} /$ $\mathrm{min} / 1.73$ in diclofenac group to $12.22 \pm 4.33 \mathrm{ml} / \mathrm{min} / 1.37, \mathrm{p}=0.0138$. In addition, pentoxifylline reduced KIM- 1 from $269.03 \pm 29.61 \mathrm{pg} / \mathrm{ml}$ in diclofenac group to $71.6 \pm 31.36 \mathrm{pg} / \mathrm{ml}$ significantly $\mathrm{p}=0.0001$. As well, pentoxifylline reduced vitronectin serum level to $1.35 \pm 0.699 \mathrm{ng} / \mathrm{ml}$ compared to $2.47 \pm 0.89 \mathrm{ng} / \mathrm{ml}$ in diclofenac group, $\mathrm{p}=0.0142$. Accordingly, pentoxifylline illustrated insignificant effect on the other renal biomarkers $\mathrm{p}>0.05$, as shown in Table 2 .

In addition, pentoxifylline produced insignificant effect in reduction cystatin-c serum levels, $\mathrm{p}=0.67$ (Fig. 2)

\section{DISCUSSION}

Diclofenac-induced nephrotoxicity has been broadly studied in the past and become one of imperative and usual model of drug-induced nephrotoxicity. However, numerous controversies are still about the major mechanism of toxicity and the latent role of different biomarkers concerning inflammatory and pro-inflammatory cytokines [17].

The present study illustrated significant nephrotoxicity which induced by diclofenac through elevation of blood urea and serum creatinine compared to the control in the experimental rats as supported by Alabi et al. [18].

Oxidative stress, free radical generations, lipid peroxidations, and diminution of endogenous antioxidant capacity are the chief mechanisms of diclofenac-induced nephrotoxicity as explained by Hickey et al. study that demonstrated a high dose of diclofenac administration lead to significant lipid peroxidation through elevation of MDA and reduction of SOD-1. As a result, free radicals lead to mitochondrial damage and reduction in the ATP formation causing DNA damage which eventually leads to acute renal injury [19]. However, in the present study, there was insignificant elevation in MDA serum level and insignificant reduction in the antioxidant capacity (SOD-1, GSH), respectively, which might due to insufficient diclofenac dose, small sample size, or short duration of experimental study.

Many cytokines are elevated during diclofenac-induced nephrotoxicity that reflects the inflammatory process in the renal tissues. Bunel 
Table 1: Effect of diclofenac on the anthropometric variables, biochemical and inflammatory biomarkers in diclofenac-induced nephrotoxicity

\begin{tabular}{|c|c|c|c|}
\hline Variable & Control $(n=10)$ & Diclofenac $(n=10)$ & $\mathbf{p}$ \\
\hline Weight (g) & $268.00 \pm 25.01$ & $286.87 \pm 27.24$ & 0.20 \\
\hline Height $(\mathrm{cm})$ & $21.50 \pm 0.83$ & $21.51 \pm 0.53$ & 0.19 \\
\hline $\operatorname{BMI}\left(\mathrm{g} / \mathrm{cm}^{2}\right)$ & $0.57 \pm 0.02$ & $0.64 \pm 0.03$ & $0.0003^{*}$ \\
\hline Blood urea (mg/dL) & $41.83 \pm 7.46$ & $70.50 \pm 12.53$ & $0.0003^{*}$ \\
\hline Serum creatinine $(\mathrm{mg} / \mathrm{dL})$ & $0.70 \pm 0.14$ & $1.52 \pm 0.49$ & $0.0019 *$ \\
\hline Estimated GFR (ml/min/1.73) & $16.89 \pm 4.21$ & $7.59 \pm 1.7$ & $0.0001^{*}$ \\
\hline MDA (ng/mL) & $289.85 \pm 44.18$ & $427.65 \pm 210.39$ & 0.14 \\
\hline $\mathrm{GSH}(\mu \mathrm{g} / \mathrm{mL})$ & $15.94 \pm 2.39$ & $14.88 \pm 3.02$ & 0.49 \\
\hline IL-18 (pg/mL) & $29.79 \pm 3.27$ & $39.37 \pm 24.74$ & 0.36 \\
\hline KIM-1 (pg/mL) & $73.78 \pm 16.29$ & $269.03 \pm 29.61$ & $0.0001^{*}$ \\
\hline NGAL (pg/mL) & $15.78 \pm 3.07$ & $18.76 \pm 4.13$ & 0.16 \\
\hline ITG (ng/mL) & $1.47 \pm 0.71$ & $2.11 \pm 0.65$ & 0.10 \\
\hline VTN (ng/mL) & $1.99 \pm 0.11$ & $2.47 \pm 0.89$ & 0.21 \\
\hline
\end{tabular}

${ }^{*} \mathrm{p}<0.01$; unpaired $t$-test, BMI: Body mass index; GFR: Glomerular filtration rate; MDA: Malondialdehyde; SOD-1: Superoxide dismutase; GSH: Glutathione reductase; IL-18: Interleukin-18; KIM-1: Kidney injury molecule-1; Cys-C: Cystatin; NGAL: Neutrophil gelatinase-associated lipocalin; ITG: Integrin; vitronectin

Table 2: Effect of pentoxifylline on the anthropometric variables, biochemical and inflammatory biomarkers in diclofenac-induced nephrotoxicity

\begin{tabular}{lll}
\hline Variable & Diclofenac (n=10) & Pentoxifylline (n=10) \\
\hline Weight $(\mathrm{g})$ & $286.87 \pm 27.24$ & $281.37 \pm 29.712$ \\
Height $(\mathrm{cm})$ & $21.00 \pm 0.53$ & $22.50 \pm 0.92$ \\
BMI $\left(\mathrm{g} / \mathrm{cm}^{2}\right)$ & $0.64 \pm 0.03$ & $0.75 \pm 0.01$ \\
Blood urea $(\mathrm{mg} / \mathrm{dL})$ & $70.50 \pm 12.53$ & $64.75 \pm 27.48$ \\
Serum creatinine $(\mathrm{mg} / \mathrm{dL})$ & $1.52 \pm 0.49$ & $0.0013^{*}$ \\
Estimated GFR (ml/min/1.73) & $7.59 \pm 1.7$ & 0.59 \\
MDA $(\mathrm{ng} / \mathrm{mL})$ & $427.65 \pm 210.39$ & $12.22 \pm 4.33$ \\
SOD-1 $(\mathrm{pg} / \mathrm{mL})$ & $30.62 \pm 15.54$ & $283.75 \pm 56.89$ \\
GSH $(\mu \mathrm{g} / \mathrm{mL})$ & $14.88 \pm 3.02$ & $42.00 \pm 27.52$ \\
IL-18 $(\mathrm{pg} / \mathrm{mL})$ & $39.37 \pm 24.74$ & $20.64 \pm 8.89$ \\
KIM-1 $(\mathrm{pg} / \mathrm{mL})$ & $269.03 \pm 29.61$ & $29.41 \pm 12.99$ \\
NGAL $(\mathrm{pg} / \mathrm{mL})$ & $18.76 \pm 4.13$ & $71.6 \pm 31.36$ \\
ITG $(\mathrm{ng} / \mathrm{mL})$ & $2.11 \pm 0.65$ & $16.78 \pm 3.79$ \\
VTN $(\mathrm{ng} / \mathrm{mL})$ & $2.47 \pm 0.89$ & 0.0138 \\
\hline
\end{tabular}

${ }^{*} \mathrm{p}<0.01 ; \mathrm{p}<0.05$ unpaired $t$-test, BMI: Body mass index; GFR: Glomerular filtration rate; MDA: Malondialdehyde; SOD-1: Superoxide dismutase; GSH: Glutathione reductase; IL-18: Interleukin-18; KIM-1: Kidney injury molecule-1; Cys-C: Cystatin; NGAL: Neutrophil gelatinase-associated lipocalin; ITG: Integrin; vitronectin

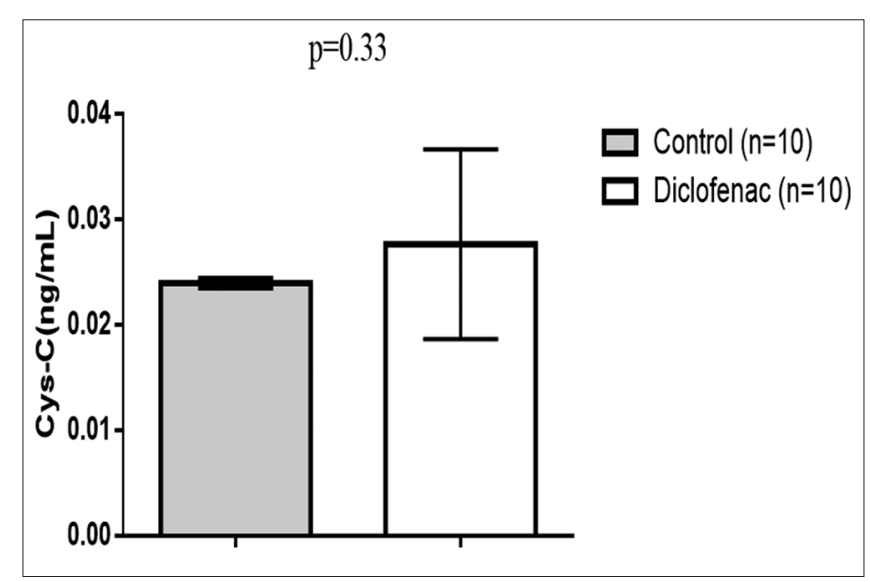

Fig. 1: Cystatin-C serum levels in diclofenac-induced nephrotoxicity

et al. study showed that IL-18, NGAL, ITG, and VTN sera levels were significantly increased within a short period of renal injury (within h) and return to the normal levels within few days due to partial regeneration of damaged renal tubules [20]. This may explain the insignificant elevated levels of these biomarkers in the present study. In addition, renal biomarkers are subjected to different inconsistency including dynamic of their excretion, diurnal variations, and baseline assessment as supported by Harrill et al. study that confirmed the variable results of the present study [21].

On the contrary, Fu et al. illustrated significant role of vitronectin and integrin in the detection of diabetes-induced renal injury [22]. As well, Kim et al. study showed that elevation of NGAL serum level is correlated with renal tubular damage in diabetic nephropathy; thus, NGAL reflects independently early proximal renal tubules damage [23]. Furthermore, KIM-1 was significantly elevated in the present study compared to the control. Lan et al. study confirmed a significant elevation of KIM-1 in cadmium-induced nephrotoxicity [24].

Harman et al. study confirmed that cystatin-C is a surrogate biomarker for acute renal injury and should be incorporated in the estimation of GFR [25], but cystatin-C serum levels in diclofenac-induced nephrotoxicity of the present study were elevated insignificantly compared to the control which might due to small sample size, biomarker variability, and short duration of the study. These factors may contribute into the insignificant elevation of cystatin-C in diclofenac-induced nephrotoxicity in rats' model of the current study.

Pentoxifylline once co-administrated with diclofenac it created a significant reduction in rat BMI compared to the diclofenac group due to the reduction of diclofenac-induced nephrotoxicity and amelioration of edematous status through enhancement of rat GFR, given that, pentoxifylline improves renal functions with significant protection of renal tubules against diclofenacinduced renal tubules injury. However, blood urea and serum creatinine were not reduced by the effect of pentoxifylline. 


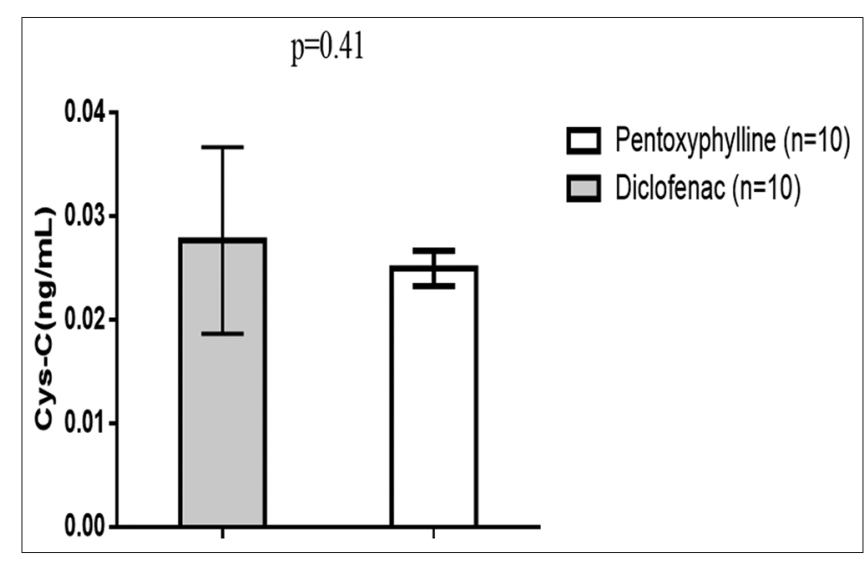

Fig. 2: Pentoxifylline produced insignificant reduction in cystatin-C serum levels in diclofenac-induced nephrotoxicity

Pentoxifylline in the present study produced insignificant attenuation of diclofenac-induced oxidative stress. This not corresponds with a recent study that confined the renoprotective effect of pentoxifylline through attenuation of oxidative stress in rate model study. The insignificant findings might due to short duration of the experimental study or inadequate dose of pentoxifylline to create a sufficient effect on oxidative stress since the duration of Ozturk et al. study was 4 weeks to show the protective effect of pentoxifylline on oxidative renal damage [26].

Indeed, pentoxifylline reduced KIM-1 and VTN serum levels significantly, but it produced insignificant effect on the other biomarkers compared to the diclofenac group. Thus, nephroprotective effect of pentoxifylline was mainly due to the reduction of KIM-1 in the present study as supported by Soni et al. study [27].

In addition, pentoxifylline produced insignificant reduction in cystatin-C serum levels in diclofenac-induced nephrotoxicity. Cystatin-C serum levels are correlated with the severity of acute renal injury and nephrotoxicity, so it used as a proxy biomarker for diagnosis and prognosis of acute renal injury [28]. However, pentoxifylline reduced cystatin- $C$ in the present study but not significant level which might due to low dose or short period of the study which limits the cytoprotective effect of pentoxifylline as confirmed by Selvin et al. study that illustrated the variability in renal biomarkers [29].

\section{CONCLUSION}

Pentoxifylline produced significant nephroprotective effect on diclofenac-induced nephrotoxicity through modulation of inflammatory biomarkers.

\section{AUTHORS' CONTRIBUTIONS}

All authors contribute equally in data collection, experimental design, interpretation, statistical analysis, literature review, manuscript preparation, and review.

\section{CONFLICTS OF INTEREST}

There are no conflicts of interest to declare.

\section{REFERENCES}

1. Mohammad A, Mruthunjaya K, Nandini C, Nabeel K, Manjula SN. Chemoprotective effect of noni (Morinda citrifolia L.) fruit juice against cisplatin-induced nephrotoxicity. Int J Pharm Pharm Sci 2016;8:105-10.

2. Pendergraft WF $3^{\text {rd }}$, Herlitz LC, Thornley-Brown D, Rosner M, Niles JL. Nephrotoxic effects of common and emerging drugs of abuse. Clin J Am Soc Nephrol 2014;9:1996-2005.

3. Geetha K, Ramarao N, Sindhu B, Rao VU. Nephroprotective, nephrocurative activity of Mimosa pudica root against gentamicin induced nephrotoxicity. Int J Pharm Pharm Sci 2015;7:173-7.

4. Altman R, Bosch B, Brune K, Patrignani P, Young C. Advances in NSAID development: Evolution of diclofenac products using pharmaceutical technology. Drugs 2015;75:859-77.

5. Inoue $\mathrm{T}$, Anai $\mathrm{S}$, Onishi $\mathrm{S}$, Miyake $\mathrm{M}$, Tanaka $\mathrm{N}$, Hirayama $\mathrm{A}$, et al. Inhibition of COX-2 expression by topical diclofenac enhanced radiation sensitivity via enhancement of TRAIL in human prostate adenocarcinoma xenograft model. BMC Urol 2013;13:1.

6. Yasmeen T, Qureshi GS, Perveen S. Adverse effects of diclofenac sodium on renal parenchyma of adult albino rats. J Pak Med Assoc 2007:57:349-51.

7. Al-Kuraishy HM, Al-Gareeb AI. Potential effects of pomegranate on lipid peroxidation and pro-inflammatory changes in daunorubicininduced cardiotoxicity in rats. Int J Prev Med 2016;7:85.

8. Siang R, Teo SY, Lee SY, Basavaraj AK, Koh RY, Rathbone MJ. Formulation and evaluation of topical pentoxifylline-hydroxypropyl methylcellulose gels for wound healing application. Int J Pharm Pharm Sci 2014;6:535-9.

9. Rodríguez-Morán M, Guerrero-Romero F. Efficacy of pentoxifylline in the management of microalbuminuria in patients with diabetes. Curr Diabetes Rev 2008;4:55-62.

10. Sun HK, Lee YM, Han KH, Kim HS, Ahn SH, Han SY. Phosphodiesterase inhibitor improves renal tubulointerstitial hypoxia of the diabetic rat kidney. Korean J Intern Med 2012;27:163-70.

11. Rübe CE, Wilfert F, Uthe D, Schmid KW, Knoop R, Willich N, et al. Modulation of radiation-induced tumour necrosis factor $\alpha$ (TNF- $\alpha$ ) expression in the lung tissue by pentoxifylline. Radiother Oncol 2002;64:177-87.

12. Navarro-González JF, Muros M, Mora-Fernández C, Herrera $\mathrm{H}$, Meneses B, García J. Pentoxifylline for renoprotection in diabetic nephropathy: The PREDIAN study. rationale and basal results. J Diabetes Complications 2011;25:314-9.

13. Navarro JF, Mora C, Muros M. Effects of pentoxifylline administrationon urinary N-acetyl-b-glucosaminidase excretion in Type 2 diabeticpatients: A short-term, prospective, randomized study. Am J Kidney 2003;42:264-70

14. Singh AP, Junemann A, Muthuraman A, Jaggi AS, Singh N, Grover K, et al. Animal models of acute renal failure. Pharmacol Rep 2012;64:31 44

15. Al-Kuraishy HM, Al-Gareeb AI, Al-Buhadilly AK. Rosuvastatin improves vaspin serum levels in obese patients with acute coronary syndrome. Diseases 2018;6:9.

16. Gacka E, Życzkowski M, Bogacki R, Paradysz A, Hyla-Klekot L. The usefulness of determining neutrophil gelatinase-associated lipocalin concentration excreted in the urine in the evaluation of cyclosporine a nephrotoxicity in children with nephrotic syndrome. Dis Markers 2016;2016:6872149.

17. de Almeida P, Tomazoni SS, Frigo L, de Carvalho PD, Vanin AA, Santos LA, et al. What is the best treatment to decrease proinflammatory cytokine release in acute skeletal muscle injury induced by trauma in rats: Low-level laser therapy, diclofenac, or cryotherapy? Lasers Med Sci 2014;29:653-8.

18. Alabi QK, Akomolafe RO, Adefisayo MA, Olukiran OS, Nafiu AO, Fasanya MK, et al. Kolaviron attenuates diclofenac-induced nephrotoxicity in male Wistar rats. Appl Physiol Nutr Metab 2018;43:956-68.

19. Hickey EJ, Raje RR, Reid VE, Gross SM, Ray SD. Diclofenac induced in vivo nephrotoxicity may involve oxidative stress-mediated massive genomic DNA fragmentation and apoptotic cell death. Free Radic Biol Med 2001;31:139-52.

20. Bunel V, Tournay Y, Baudoux T, De Prez E, Marchand M, Mekinda Z, et al. Early detection of acute cisplatin nephrotoxicity: Interest of urinary monitoring of proximal tubular biomarkers. Clin Kidney J 2017;10:639-47.

21. Harrill AH, Lin H, Tobacyk J, Seely JC. Mouse population-based evaluation of urinary protein and miRNA biomarker performance associated with cisplatin renal injury. Exp Biol Med (Maywood) 2018;243:237-47.

22. Fu G, Du Y, Chu L, Zhang M. Discovery and verification of urinary peptides in Type 2 diabetes mellitus with kidney injury. Exp Biol Med (Maywood) 2016;241:1186-94

23. Kim SY, Jeong TD, Lee W, Chun S, Sunwoo S, Kim SB, et al. Plasma neutrophil gelatinase-associated lipocalin as a marker of tubular damage in diabetic nephropathy. Ann Lab Med 2018:38:524-9.

24. Lan Z, Bi KS, Chen XH. Ligustrazine attenuates elevated levels of indoxyl sulfate, kidney injury molecule-1 and clusterin in rats exposed 
to cadmium. Food Chem Toxicol 2014;63:62-8.

25. Harman G, Akbari A, Hiremath S, White CA, Ramsay T, Kokolo MB, et al. Accuracy of cystatin C-based estimates of glomerular filtration rate in kidney transplant recipients: A systematic review. Nephrol Dial Transplant 2013;28:741-57.

26. Ozturk H, Cetinkaya A, Firat TS, Tekce BK, Duzcu SE, Ozturk H, et al. Protective effect of pentoxifylline on oxidative renal cell injury associated with renal crystal formation in a hyperoxaluric rat model. Urolithiasis 2018;6:1.

27. Soni HM, Patel PP, Patel S, Rath AC, Acharya A, Trivedi HD, et al.
Effects of combination of aliskiren and pentoxyfylline on renal function in the rat remnant kidney model of chronic renal failure. Indian $\mathrm{J}$ Pharmacol 2015;47:80-5.

28. Leem AY, Park MS, Park BH, Jung WJ, Chung KS, Kim SY, et al. Value of serum cystatin $\mathrm{c}$ measurement in the diagnosis of sepsis induced kidney injury and prediction of renal function recovery. Yonsei Med J 2017;58:604-12.

29. Selvin E, Juraschek SP, Eckfeldt J, Levey AS, Inker LA, Coresh J. Within-person variability in kidney measures. Am J Kidney Dis 2013;61:716-22. 